\title{
ACTIVE PHENOLIC CONSTITUENTS AND BRINE SHRIMP LETHALITY ASSAY OF HYDROALCOHOLIC EXTRACT OF PLECTRANTHUS AMBOINICUS
}

\author{
DAYANA JANAKIRAMAN ${ }^{1}$, PARAMESWARI CS ${ }^{2 *}$ \\ ${ }^{1}$ Post Graduate and Research Department of Biochemistry, Bharathi Women's College, Chennai, Tamil Nadu, India. ${ }^{2}$ Principal, Government \\ Arts College for Women, Ramanadapuram, Tamil Nadu, India. Email: cspresearch12@gmail.com
}

Received: 08 September 2016, Revised and Accepted: 25 October 2016

\section{ABSTRACT}

Objective: Plectranthus amboinicus (PA) leaves contain pharmaceutically important phytoconstituents that attribute to greater medicinal values. The purpose of this study was to investigate the active principles present in the potent hydroalcoholic extract of PA (HAPA) and brine shrimp lethality studies to understand the toxicity profile of PA, to unravel many potential applications in the field of science.

Methods: An approach toward high performance liquid chromatography (HPLC) screening of (HAPA) and selective partitioning using various solvents such as hexane, chloroform, ethyl acetate, and butanol were performed to identify the active principles present. Acute oral toxicity or brine shrimp lethality studies on Artemia salina L. using active fraction of PA were also attempted.

Results: The HPLC profile of ethyl acetate fraction of hydroalcoholic extract showed flavonoids such as Rutin, quercetin, luteolin and gallic acid, which was found to be considerably different from hydroalcoholic extract and this fraction also showed good acute oral toxicity effect and the LC50 value obtained was $198.630 \mu \mathrm{g} / \mathrm{ml}$.

Conclusion: These results attribute to the pharmacological importance of the plant. Selective isolation of individual phytochemical constituents and subjecting it to biological testing will definitely give promising results for the medicinal field.

Keywords: High performance liquid chromatography, Plectranthus amboinicus, Artemia salina L., Brine shrimp, Phenolic constituents.

(c) 2017 The Authors. Published by Innovare Academic Sciences Pvt Ltd. This is an open access article under the CC BY license (http://creativecommons. org/licenses/by/4. 0/) DOI: http://dx.doi.org/10.22159/ajpcr.2017.v10i2.15115

\section{INTRODUCTION}

Herbal immunosuppression: Herbal drugs are known to possess immunomodulatory properties and generally act by stimulating both specific and nonspecific immunity. Many plants used in traditional medicine have immunomodulating activities, where activation of $\mathrm{T}$ and B lymphocytes, macrophages, and apoptosis of immune effector cells play critical roles [1,2]. Herbal drugs have gained importance and popularity because of their safety, efficacy, and cost-effectiveness.

Plectranthus amboinicus (Lour) (PA) Spreng, commonly called as country borage or Indian borage is a native plant of Taiwan. It is a large succulent aromatic perennial herb, shrubby below, hispidly villous, or tomentose $[3,4]$. Juice of leaves mixed with sugar acts as a powerful aromatic carminative, given in colic and dyspepsia [5]. The antibacterial [6], antifungal, anti-inflammatory [7], antidiabetic, antioxidant, antinociceptive, antihelminthic, and hepatoprotective nature of PA were studied and reported by many scientists worldwide. PA is considered as a useful medicinal plant because it contains lots of bioactive compounds which actively play a role for immune response.

Medicinal plants are gaining importance due to their positive effects with no harmful results. Thus, to enhance the health status, with a deep insight of phytochemical constituents present in them, an attempt toward studying active phenolic constituents of hydroalcoholic extract of PA (HAPA) and acute oral toxicity bioassay on Artemia salina L. were performed.

\section{METHODS}

Collection and preparation of plant extract

Fresh leaves of PA were collected from a local garden in Chennai during the month of August. The leaves were authenticated by Prof. Dr. P Jayaraman, Director, Plant Anatomy Research Centre (PARC),
Chennai, India. A voucher specimen (No: PARC/2013/2063) was deposited in the institution.

About $1 \mathrm{~kg}$ of powdered dry leaves was incubated with $70 \%$ hydroalcohol for $48 \mathrm{hrs}$ in a mechanical shaker. The extract was concentrated using a rotary evaporator, and the distilled solvent was collected. The crude extract was now reincubated with Hexane, chloroform, ethyl acetate and butanol successively in a separating funnel for $1 \mathrm{hr}$ and the solvent phase formed as a separate layer was removed, respectively, and analyzed qualitatively for flavonoids (Shinoda and Lead acetate tests) $[8,9]$.

\section{High-performance liquid chromatography (HPLC)}

The HAPA which possessed good anti-inflammatory, antioxidant capacity and notable phenolic content as reported in our earlier studies $[10,11]$ was subjected to HPLC analysis for quantitative interpretation of compounds present in it. Later, the ethyl acetate fraction of HAPA (EAHAPA), which answered positively for flavonoids, was subjected to HPLC analysis for quantitative interpretation of compounds present in it with the same set of parameters.

C18 column of MERCK make was used for HPLC run. Mixture of alcohol, water and hydrochloric acid (50:20:8) was used as extraction solvent. Mixture of methanol, water and phosphoric acid was prepared in the ratio 100:100:1 and adjustments were made if necessary and used as mobile phase. Sample flow rate was at $1 \mathrm{ml} / \mathrm{min}$. The injection volume was $20 \mu \mathrm{l}$ and the eluate was monitored at $270 \mathrm{~nm}$.

The HAPA and EAHAPA were injected under these conditions along with the authentic samples of rutin, quercetin, luteolin, kaempferol, and gallic acid (prepared as $1 \mathrm{mg} / \mathrm{ml}$, respectively). The chromatograms obtained were recorded and areas of major peaks were measured. The percentages of each phenolic and flavonoid samples were calculated 
using authentic standards. The purity of each identified peak was determined by comparison of the retention times and ultraviolet spectra at upslope and downslope inflexion points from available literature sources.

\section{Acute oral toxicity studies using $A$. salina $L$.}

Lethal toxicity assay an emerging new assay for determining oral toxicity is done based on the method of Meyer et al. and Solis et al. [12,13]. It is also done to assess cytotoxicity $[13,14]$.

About 10 shrimps were transferred to each test tube and artificial sea water was added to make $5 \mathrm{~mL}$. Samples were prepared at different concentrations and diluted appropriately and transferred to each tube. The nauplii can be counted macroscopically in capillary against a lighted background. The test tubes were maintained under illumination. Survivors were counted; with the aid of the $\times 3$ magnifying glass for every $3 \mathrm{hrs}$ up to $24 \mathrm{hrs}$ and the percentage death at each dose were determined. 24 hrs count was more useful.

The percentage of mortality in each concentration was determined, and LC50 values were obtained from the best fit line plotted with concentration versus percentage lethality using Microsoft Excel 2007 using linear regression analysis.

\section{RESULTS}

The HPLC analysis of the hydroalcoholic extract revealed the presence of various flavonoid compounds including quercetin, vitexin, rutin, luteolin, hispidulin (Fig. 1 and Table 1) and phenolic constituents including hydroxy benzoic acid, vanillic acid, gallic acid, coumaric acid, syringic acid, caffeic acid, and cinnamic acid (Fig. 2 and Table 2).

Further purification of hydroalcoholic extract using different solvents such as hexane, chloroform, ethyl acetate, and butanol based on polarity were done by successive extraction using separating funnel. Among which ethyl acetate fraction alone showed a significant presence of flavonoid compounds and was analyzed in HPLC column with the same set of parameters.

The HPLC profile of EAHAPA showed flavonoids such as rutin, quercetin, luteolin, and gallic acid (Fig. 3 and Table 3). The compounds were quantified and were expressed in $\mathrm{mg} / \mathrm{g}$ units.

The results were also compared with the standard graphs of rutin, luteolin, gallic acid, galangin, etc., (Figs. 4 and 5).

\section{Acute oral toxicity assay}

Acute oral toxicity assay of EAHAPA was done with concentration ranging from $50,100,200,400$ and $800 \mu \mathrm{g} / \mathrm{ml}$, respectively.

Fig. 6 shows the graph of lethal toxicity assay for dosage fixation study plotted for concentration in $\mu \mathrm{g} / \mathrm{ml}$ of EAHAPA (X-axis) against $\%$ mortality (Y-axis) of brine shrimps and linear regression analysis done showing equation $(y=0.073 x+35.50)$ and $R^{2}=0.791$ value obtained for it. The LC50 value thus obtained is $198.630 \mu \mathrm{g} / \mathrm{ml}$.

\section{DISCUSSION}

\section{HPLC}

The HPLC chromatograms of crude leaf extracts of PA indicated the presence of phenolics like caffeic acid, coumaric acid, rutin, quercetin and gallic acid, which were present in the range of $0.01-1.41 \mathrm{mg} / \mathrm{g}$ in ethyl acetate and $0.03-1.93 \mathrm{mg} / \mathrm{g}$ in the acetone extract [15]. Antibacterial compounds - 1, 2-Benzene diol 4-(1, 1 dimethyl ethyl), phytol, squalene and eudesma-4(14), 11-diene have been isolated from the acetone extract by gas chromatography-mass spectrometry (GC-MS) analysis done by Jasmine and Selvi, 2013 [16].

The chemical entities identified from plants vary according to geographical location, time and season of collection. Chemical entities including carvacrol, caryopyllene, thymol, eugenol, patchoulane, chacicol, and flavonoids have been reported to be isolated from Coleus aromaticus. Monoterpenes and sesquiterpenes have been reported

Table 1: Flavonoid compounds present in HAPA

\begin{tabular}{lll}
\hline Flavonoids & Retention time (minutes) & mg/g \\
\hline Quercetin & 3.37 & 5.43 \\
Vitexin & 4.13 & 0.102 \\
Rutin & 8.17 & 1.264 \\
Luteolin & 10.19 & 1.05 \\
Hispidulin & 20.98 & 0.21 \\
\hline
\end{tabular}

HAPA: Hydroalcoholic extract of plectranthus amboinicus

Table 2: Phenolic compounds present in HAPA

\begin{tabular}{lll}
\hline Phenols & Retention time (minutes) & mg/g \\
\hline Vallinic acid & 2.78 & 2.12 \\
Hydroxy Benzoic acid & 3.76 & 1.44 \\
Gallic acid & 4.04 & 0.93 \\
Coumaric acid & 4.68 & 1.68 \\
Syringic acid & 5.91 & 1.22 \\
Caffeic acid & 6.91 & 2.26 \\
Cinnamic acid & 11.68 & 0.28 \\
\hline
\end{tabular}

HAPA: Hydroalcoholic extract of plectranthus amboinicus

Table 3: Flavonoid compounds present in EAHAPA

\begin{tabular}{lll}
\hline Flavonoids & Retention time (minutes) & mg/g \\
\hline Quercetin & 3.19 & 0.536 \\
Gallic acid & 4.08 & 0.327 \\
Rutin & 7.47 & 0.059 \\
Luteolin & 10.18 & 0.34 \\
\hline
\end{tabular}

EAHAPA: Ethyl acetate fraction of hydroalcoholic extract of Plectranthus amboinicus

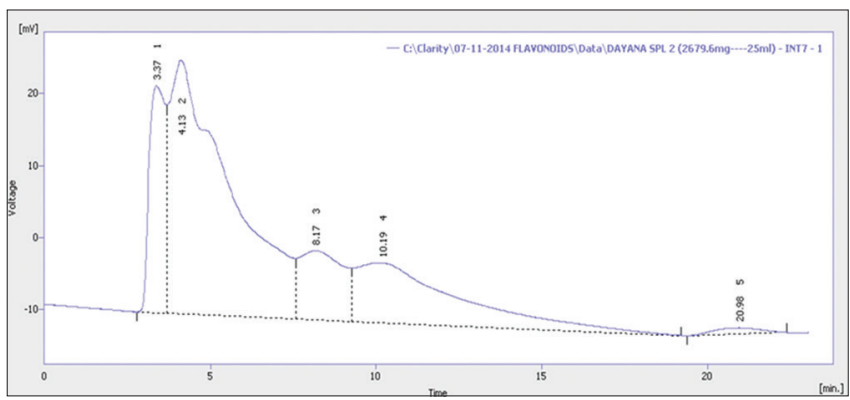

Fig. 1: High performance liquid chromatography chromatogram showing flavonoids of hydroalcoholic extract of Plectranthus amboinicus

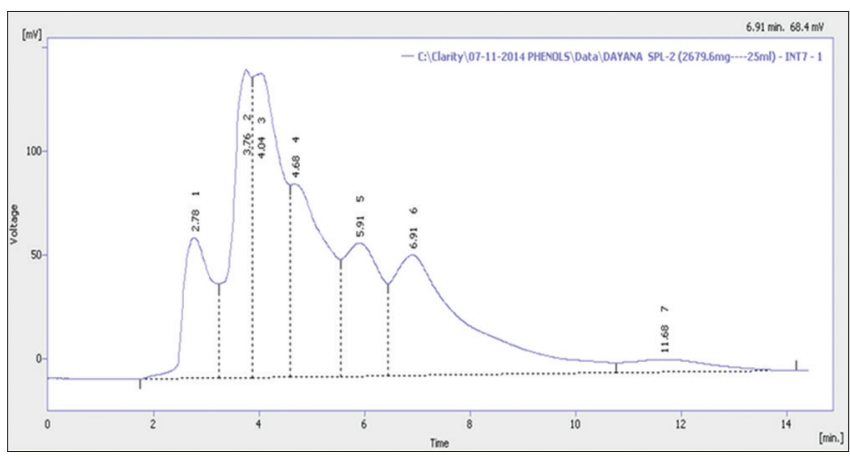

Fig. 2: High performance liquid chromatography chromatogram showing phenolic compounds of hydroalcoholic extract of plectranthus amboinicus 


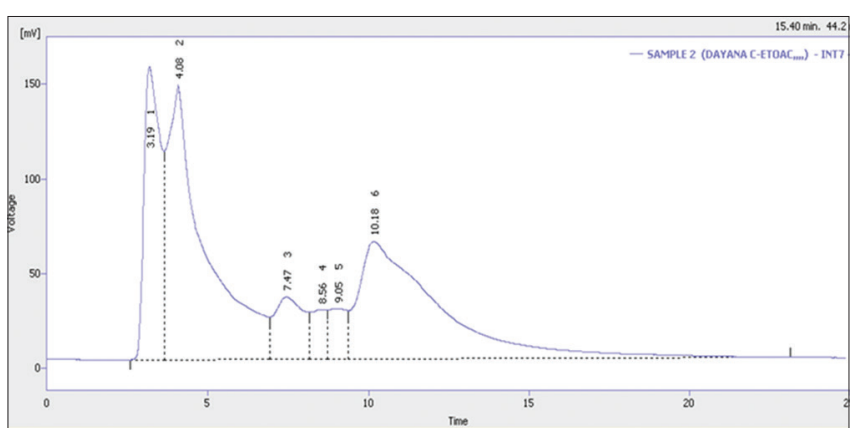

Fig. 3: High performance liquid chromatography chromatogram of ethyl acetate fraction of hydroalcoholic extract of Plectranthus amboinicus

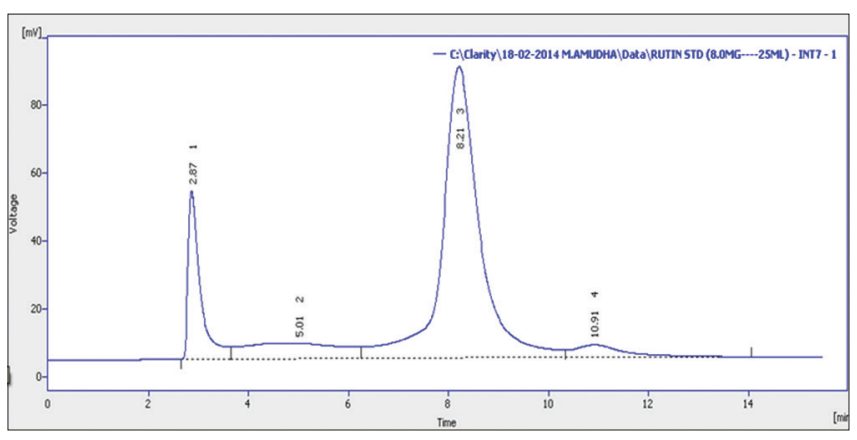

Fig. 4: High performance liquid chromatography chromatogram of standards rutin and luteolin

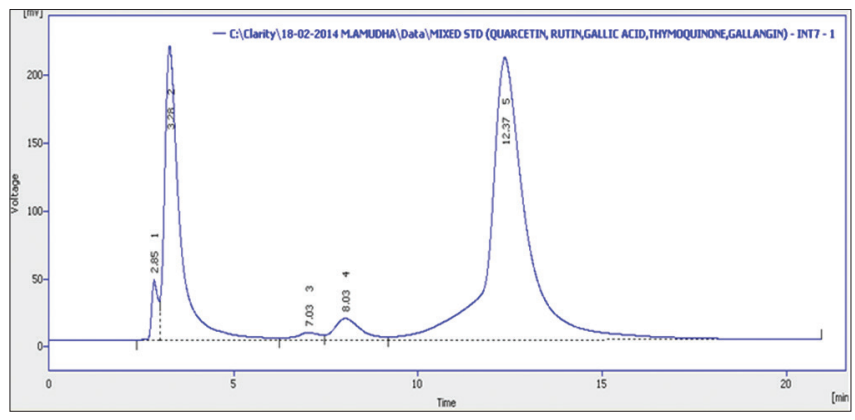

Fig. 5: High performance liquid chromatography chromatogram of standards quercetin, galangin, gallic acid and thymoquinone

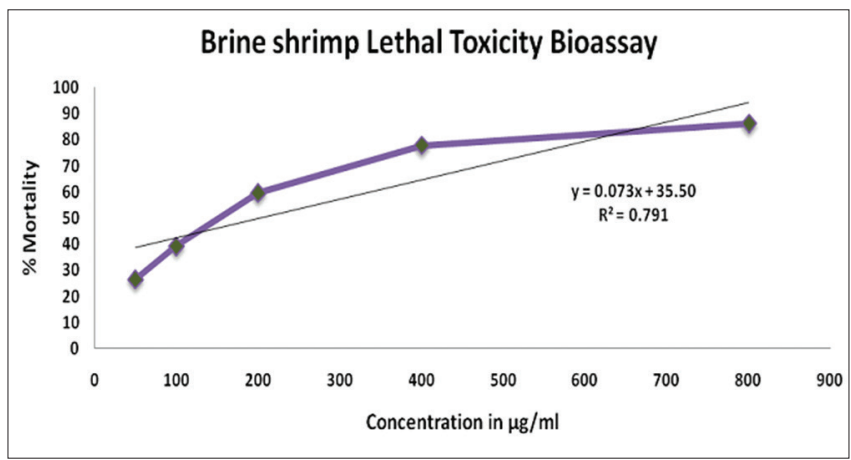

Fig. 6: Lethal toxicity assay of brine shrimp and linear regression analysis plot showing the $R^{2}$ value and the equation of the line

from C. aromaticus which had antimicrobial activity including limonene, linalool, myrcene and thymol also, alpha-amorphene, beta cubebene, and phenolics [17].
GC-MS characterization of essential oils from roots, stem and leaves of two Plectranthus genus (Plectranthus barbatus and Plectranthus caninus) cultivated in northern Italy were done by steam distillation and chemical structures were characterized. The leaves showed the second highest yield $(64.34$ and $26.65 \mathrm{mg} / \mathrm{kg}$ ) followed by roots and stems. 128 and 121 structures were identified respectively [18]

Leaves of C. aromaticus contain flavones salvigenin, 6-methoxygenkwanin, quercetin, chrysoeriol, luteolin and apigenin, the flavanone eriodyctol and the flavanol taxifolin, triterpenic acids; oleanolic acid, 2,3-dihydroxyoleanolic acid, crategolic acid, ursolic acid, pomolic acid, euscaphic acid, tormentic acid, and 2,3,19,23-tetrahydroxyursolic acid as reported by Sahaykhare et al. [19]. The major compounds including carvocrol, thymol, Cis-caryophyllene, $\mathrm{t}$-caryophyllene, and p-cymene were reported by GC-MS analysis of PA essential oil [20].

\section{Acute oral toxicity assay}

The percentage of mortality increases with the increase in concentration of test samples. Brine shrimp lethality bioassay (BST) is an efficient, rapid and inexpensive assay for testing the bioactivity of plant extracts. It is an excellent choice for elementary toxicity investigations based on the ability to kill laboratory-cultured Artemia nauplii [21]. A positive correlation between the lethality to brine shrimp and the corresponding oral lethal dose in mice of medicinal plants has also been demonstrated [22].

Similar results were observed in Elaeis guineensis methanolic extract [23] after $24 \mathrm{hrs}$ was $3.87 \mathrm{mg} / \mathrm{ml}$. Sahqal et al., 2010, [24] also studied for brine shrimp lethality on Swietenia mahagoni (Linn.) Jacq. seed methanolic extract and analyzed moderate cytotoxicity at high concentration with LC50 value for the extract was $0.68 \mathrm{mg} / \mathrm{ml}$.

\section{CONCLUSION}

This study has been found useful, where a variety of active compounds have been found in HAPA. The presence of various bioactive compounds such as vanillic acid, hydroxy benzoic acid, Gallic acid, Coumaric acid, syringic acid, caffeic acid and cinnamic acid, and flavonoids including quercetin, vitexin, rutin, luteolin and hispidulin, essential oils, terpenoids, sugars, aromatic aldehydes justifies the use of the plant for various ailments by traditional practitioners. The analysis time is an important factor in analytical work and the run time should be reduced to a minimum to optimize equipment use and reduce solvent consumption [25].

It could be concluded that PA plant is of phytopharmaceutical importance. However, isolation of individual phytochemical constituents and subjecting it to biological testing will definitely land down in promising results.

In this study, the brine shrimp lethality bioassay was performed to assess the preliminary toxicity of PA and dosage of $200 \mathrm{mg} / \mathrm{ml}(\times 1000)$ was planned for further in vivo animal studies. Even though the brine shrimp test does not provide adequate information regarding the mechanism of action of the plant extracts it is useful to assess the toxicity from the LC50 value obtained and indicates the cytotoxic nature of the plants and warrants further investigation [26].

\section{ACKNOWLEDGMENTS}

The authors thank for the financial support provided by DST_INSPIRE fellowship (AORC scheme) and Department of Biochemistry, Bharathi Women's College for the lab facilities.

\section{REFERENCES}

1. Perl A. Pathogenesis and spectrum of autoimmunity. Methods Mol Med 2004;102:1-8

2. Ramaswamy $M$, Deng $M$, Siegel RM. Harnessing programmed cell death as a therapeutic strategy in rheumatic diseases. Nat Rev 
Rheumatol 2011;7(3):152-60.

3. Kirtikar KR, Basu BD. Indian Medicinal Plants. $3^{\text {rd }}$ ed. Dehradun, India: International Book Distributors; 1999. p. 1970-1.

4. Warier PK, Nambier VP. Indian Medicinal Plants: A Compendium of 500 Species. $4^{\text {th }}$ ed. Chennai: Orient Longman Limited; 1996. p. 315.

5. Chopra RN, Nayar SL, Chopra IC. Glossary of Indian Medicinal Plants. New Delhi, India: C.S.I.R. Publications; 1999. p. 74.

6. Chandrappa MS, Harsha R, Dinesh R, Gowda SS. Antibacterial activity of Coleus aromaticus leaves. Int J Pharm Pharm Sci 2010;2(3):63-6.

7. Manjamalai A, Narala Y, Haridas A, Berlin Grace VM. Antifungal, anti-inflammatory and GC-MS analysis of methanolic extract of Plectranthus amboinicus leaf. Int J Curr Pharm Res 2011;3(2):129-36.

8. Raman N. Phytochemical Techniques. New Delhi: New India Publishing Agency; 2006. p. 19.

9. Harborne JB. Phytochemical Methods. New Delhi: Springer (India) Pvt. Ltd.; 2005. p. 17

10. Janakiraman D, Parameswari CS. Evaluation of anti-inflammatory effect of Plectranthus amboinicus leaf extract - An in vitro study. J Adv Pharm Educ Res 2014;4(2):229-32.

11. Dayana J, Parameswari CS. New perspective of stress combating potential of Plectranthus amboinicus (Lour) leaves - An in vitro study. Int J Pharm Res Biosci 2014;3(3):452-71.

12. Meyer N, Ferrigni NR, Putnam JE. Brine shrimp: A convenient general bioassay for active plant constituents. Planta Med 1982;45:31-2.

13. Solis PN, Wright CW, Anderson MM, Gupta MP, Phillipson D. A micro well cytotoxicity using Artemia salina (Brine shrimp). Planta Med 1992;59:250-2.

14. Apu AS, Bhuyan SH, Khatun, F, Liza MS, Matin M, Hossain F. Assessment of cytotoxic activity of two medicinal plants using Brine shrimp (Artemia salina) as an experimental tool. Int J Pharm Sci Res 2013;4(3):1125-30.

15. Gupta SK, Bhatt P, Joseph GS, Negi PS, Varadaraj MC. Phenolic constituents and biological activities of leaf extract of traditional medicinal plant Plectranthus amboinicus Benth (Lamiaceae). TANG 2013;3(4):50-5.

16. Jasmine R, Selvi JS. Analysis of antibacterial activity of the bioactive constituents from the acetone extract of Coleus aromaticus (Benth)
Leaves by gas chromatography-mass spectrometry. World J Pharm Pharm Sci 2013;2(5):3088-93

17. Warrier PK, Nambiar VP, Ramankutty C. Indian Medicinal Plants. $4^{\text {th }}$ ed., Vol. 18. Madras: Orient Longman Limited; 1995. p. 315-7.

18. Gelmini F, Squillace P, Testa C, Sparacino AC, Angioletti S, Beretta G. GC-MS characterisation and biological activity of essential oils from different vegetative organs of Plectranthus barbatus and Plectranthus caninus cultivated in north Italy. Nat Prod Res 2015;29(11):993-8.

19. Sahaykhare R, Banerjee S, Kundu K. Coleus aromaticus Benth. - A nutritive medicinal plant of potential therapeutic value. Int J Pharm Biol Sci 2011;2(3):488-500

20. Arslanyolu M, Erdemgil FZ. Evaluation of the antibacterial activity and toxicity of isolated arctin from the seeds of Centaurea sclerolepis. J Fac Pharm Ankara 2006;35(2):103-9.

21. Manjamalai A, Alexander T, Berlin Grace VM. Bioactive evaluation of the essential oil of Plectranthus amboinicus by GC-MS analysis and its role as a drug for microbial infections and inflammation. Int J Pharm Pharm Sci 2012;4(3):205-11.

22. Logarto Parra A, Silva Yhebra R, Guerra Sardiñas I, Iglesias Buela L. Comparative study of the assay of Artemia salina $\mathrm{L}$. and the estimate of the medium lethal dose (LD50 value) in mice, to determine oral acute toxicity of plant extracts. Phytomedicine 2001;8(5):395-400.

23. Syahmi AR, Vijayarathna S, Sasidharan S, Latha LY, Kwan YP, Lau YL, et al. Acute oral toxicity and brine shrimp lethality of Elaeis guineensis Jacq. (oil palm leaf) methanol extract. Molecules 2010;15(11):8111-21.

24. Sahqal G, Ramanathan S, Sasidharan S, Mordi MN, Ismail S, Mansor SM. Brine shrimp lethality and acute oral toxicity studies on Swietenia mahagoni (Linn.) Jacq. seed methanolic extract. Pharm Res 2010; (4):215-20.

25. De Oliveira BH, Nakashimab T, de Souza Filhoc JD, Frehse FL. HPLC analysis of flavonoids in Eupatorium littorale. J Braz Chem Soc 2001;12(2):243-6.

26. Solanki SS, Selvanayagam M. Phytochemical screening and study of predictive toxicity of certain medicinal plants and extracts using brine shrimp. Herb Tech Ind 2013;10(1):1-4. 